EPiC Series in Language and Linguistics
Volume 2, 2017, Pages 69-74
Professional and Academic Discourse:
an Interdisciplinary Perspective

\title{
The Long-term Effects of Instruction on EFL Learners' Use of Complaining Formulas
}

\author{
Alicia Martínez-Flor and Esther Usó-Juan \\ Universitat Jaume I, Castellón, Spain \\ aflor@ang.uji.es, euso@ang.uji.es
}

\begin{abstract}
Studies analysing the positive role of pragmatic instruction in formal settings have increased over the last decades. Within this area of interventional pragmatics, some studies have particularly examined whether the effectiveness of the instruction implemented is sustained over time. In order to shed more light on the long-term effects of instruction, this research investigates English as a Foreign Language learners' use of complaining formulas not only after immediately receiving instruction, but also two months later. Results show that learners keep using a variety of appropriate complaining formulas two months after having participated in the instructional period. These findings are discussed and directions for future research suggested.
\end{abstract}

\section{Introduction}

The role of pragmatic instruction in formal academic settings has been one of the main investigated areas within the field of interlanguage pragmatics in the last decades (see Takahashi, 2010; Taguchi, 2015 for a review of the research conducted). Results from this research have overall shown the benefits of engaging learners in an instructional period as well as the teachability of all pragmatic aspects being examined (i.e. a variety of speech acts, implicature, speech style, interactional markers or address forms, among others). More specifically, it has been ascertained that instruction seems to be necessary in foreign language (FL) contexts, where learners' opportunities to be exposed to naturally occurring input, chances for communicative practice, and feedback regarding their pragmatic performance are highly limited (Martínez-Flor and Usó-Juan, 2010). Among the studies that have analysed the positive role of pragmatic instruction, some have been designed to examine the long-term effect of such an instruction (Lyster, 1994; Liddicoat and Crozet, 2001; Codina, 2008; Martínez-Flor, 2012).

Lyster's (1994) study dealt with the distinction between the use of French tu/vous in different informal and formal contexts. The instructional treatment involved a kind of functional-analytic teaching which lasted twelve hours implemented during five weeks. Results indicated that the experimental participants outperformed the control students on both oral and written ability to use vous appropriately in formal situations, and that such an improvement was retained in the delayed post-test administered one month later. In Liddicoat and Crozet’s (2001) study, which also involved learners of 
French as a FL, the instructional focus was the acquisition of one target interactional practice (i.e. responding to a question about the weekend in French). The instruction on this feature was part of a module on spoken language and culture implemented during thirteen weeks. After the treatment, findings showed that the learners used both specific language features and content closer to the French pragmatic norms. However, the delayed post-test conducted one year later proved that only the content had been retained, since the features of form, such as repetition or overlap, seemed to be similar to the ones found before the instructional sessions.

Targeting English as Foreign Language (EFL) learners, the studies by Codina (2008) and MartínezFlor (2012) focused on the use of request modification devices when requesting in a variety of situations. On the one hand, Codina (2008) incorporated explicit metapragmatic information and awareness-raising activities in three one-and-a-half-hour sessions during two weeks. After the treatment, the author found that the experimental group with an advanced level seemed to support the positive effect of instruction, which was also sustained six weeks later. In contrast, instruction did not seem to be effective for the lower proficiency learners either after immediately receiving instruction or six weeks later. On the other hand, Martínez-Flor's (2012) research showed that learners, after participating in an inductive-deductive teaching approach implemented during three two-hour sessions, employed a greater amount of appropriate request modification devices as well as a wide variety of internal and external modifiers. Additionally, such an improvement was ascertained not only after immediately participating in the instructional period, but also four months later.

In an attempt to expand this line of research, and address Kasper and Rose's (2002) suggestions regarding the need to assess the instructional effects over time, the present study examines learners' use of complaining formulas in an EFL context not only after immediately receiving instruction, but also two months later. The speech act of complaining has been selected as the instructional target feature of this study due to the fact that a performance of it in a foreign language is a complex and challenging task for learners (Trosborg, 1995). Indeed, learners' lack of the appropriate formulas to perform complaints in a socially acceptable manner in the target language may result in an impolite and rude behaviour (Usó-Juan and Martínez-Flor, 2014). Thus, there is a need to make learners aware of the different formulas that may be used when complaining in a variety of communicative situations depending on the social variables (i.e. status, distance and level of offense) and the degree of politeness involved in each situation.

Based on this assumption, Martínez-Flor and Usó-Juan (2015) examined the role of instruction on EFL learners' use of complaining-apologising semantic formulas in different contrasting situations. Focusing specifically on complaints, results showed that before participating in the instructional treatment, learners employed almost only the explicit complaint formula (i.e. you're always late) independently of the social and contextual factors involved in the situation. In contrast, after receiving instruction on how to appropriately perform complaints, a variety of complaining formulas were used including the no explicit reproach formula (i.e. never mind, nothing serious happened) as well as the use of mitigated and softened expressions of disapproval, accusation, warning and threat. As a followup study, the present investigation analyses the long-term effects of such an instruction to assess whether the effectiveness of the treatment implemented in the instructional period lasted as long as two months after it had finished. 


\section{Methodology}

Subjects for our study were 12 EFL learners, whose age ranged between 19 and 23 years old, the average age being 20.3 years $^{1 *}$. They were second-year students of the degree of English Studies, and their proficiency level of English was upper-intermediate (B2 according to the Council of Europe level) as illustrated by the Quick Placement Test (2001) that took place at the beginning of the academic year.

Learners were first distributed a pre-test (an interactive discourse completion test (IDCT) adopted from Usó-Juan and Martínez-Flor (2014), which involved four situations, each including a scenario for a complaint and an apology ${ }^{2 \dagger}$. These scenarios varied according to the sociopragmatic factors of status, distance and severity of offense in the realisation of the speech act, and consequently, two levels of status (i.e., low and high) and distance (i.e., close and distant) were considered, as well as two levels of severity of offense (i.e., less and more). The topics for these scenarios included discussions between two people as far as: a recommendation letter, a lost hotel reservation, misspelled business documents, and habitual late arrival for work. For each scenario, learners had to orally interact as in a role-play and write what they would actually say. The purpose of this pre-test was to find out learners' use of semantic formulas for complaining before the instructional period.

The treatment consisted of an approach implemented during two two-hour sessions that included both awareness and production activities as well as explicit metapragmatic explanations. The activities were adapted from the tasks developed by Usó-Juan and Martínez-Flor's (2014) and included interactions between a complainer and an apologiser in four different scenarios: cigarette breaks, a business meeting, casual conversations at front office, and false educational credentials. First, learners were presented with a variety of awareness-raising activities designed to make them aware of the pragmalinguistic and sociopragmatic aspects that influence the choice of an appropriate formula when complaining in different situations. Without checking learners' performance in those activities, the teacher explicitly showed learners the different pragmalinguistic formulas that may be used when complaining (see Table 1).

\begin{tabular}{ll}
\hline Strategies & Examples \\
\hline 1. No explicit reproach & Never mind, nothing serious happened \\
2. Expression of disapproval & What terrible bureaucracy! \\
3. Explicit complaint & You're always late \\
4. Expression of accusation & I'll speak to your supervisor \\
$\quad$ and warning & I'm not moving one inch unless you change \\
5. Expression of threat & my appointment \\
\hline
\end{tabular}

Table 1: Complaint formulas (adapted from Olshtain and Weinbach, 1987; Trosborg, 1995)

Similarly, they were explained the importance of paying attention to the sociopragmatic factors of social status, social distance and severity of offense involved in each situation for the appropriate choice of a particular complaint formula. After such an explanation and pragmatic discussion, learners were presented with production activities to make them practice the semantic formulas presented in a meaningful and communicative way. Finally, learners were provided with feedback on their complaining performance in those communicative activities.

One week after the instructional treatment had finished, learners completed the post-test, which incorporated the same situations employed in the pre-test although they were arranged in a different

\footnotetext{
* There were a total of 24 learners participating in the study. However, since they worked in pairs when doing the tasks, half of them took the role of a complainer and half an apologiser. For the purposes of the present study, we analyse only those performing as complainers.

${ }^{\dagger}$ The scenarios were designed to consider the speech act set of complaining-apology as an adjacency pair. However, for the purposes of the present study, we focus only on complaints.
} 
order. Finally, two months later, a delayed post-test, which was exactly the same as the pre-test, was administered. We examined the amount and type of complaining formulas used by learners in the three different moments (i.e. pre-test, post-test and delayed post-test) on the basis of previous research that has presented classifications of complaint formulas (see Table 1 above).

\section{Results and Discussion}

Learners' performance when complaining in the four contrasting situations included in the IDCT distributed before the instructional period, immediately after it and two months later, was analysed. Table 2 shows the results of the overall amount of complaint formulas employed by learners in the three different moments.

\begin{tabular}{lcccccc}
\hline \multicolumn{1}{c}{ Complaint formulas } & \multicolumn{2}{c}{ Pre-test } & \multicolumn{2}{c}{ Post-test } & \multicolumn{2}{c}{ Delayed post-test } \\
\hline & $n$ & $\%$ & $n$ & $\%$ & $n$ & $\%$ \\
No explicit reproach & 0 & 0.0 & 88 & 51.2 & 85 & 51.5 \\
Expression of disapproval & 5 & 4.9 & 28 & 16.3 & 26 & 15.9 \\
Explicit complaint & 95 & 90.3 & 31 & 18.1 & 30 & 18.2 \\
Expression of accusation & 3 & 2.9 & 12 & 6.9 & 12 & 7.2 \\
and warning & & & & & & 7.2 \\
Expression of threat & 2 & 1.9 & 13 & 7.5 & 12 & $\mathbf{1 0 5}$ \\
$\quad$ Total & $\mathbf{1 0 5}$ & $\mathbf{1 0 0 . 0}$ & $\mathbf{1 7 2}$ & $\mathbf{1 0 0 . 0}$ & $\mathbf{1 6 5}$ & $\mathbf{1 0 0 . 0}$ \\
\hline
\end{tabular}

Table 2: Learners' use of complaint formulas in the pre-test, post-test and delayed post-test.

Before participating in the instructional period (pre-test), learners' most frequently used formula was explicit complaint (90.3\%), and to a much lesser extent learners employed expression of disapproval (4.9\%), expression of accusation and warning (2.9\%) and expression of threat (1.9\%), with no instances at all of the no explicit reproach formula. After immediately receiving instruction (posttest), learners resorted to the use of all complaint formulas. Indeed, the no explicit reproach strategy was the highest formula used amounting to a 51.2\%, followed by explicit complaint (18.1\%), expression of disapproval (16.3\%), expression of threat (7.5\%) and expression of accusation and warning (6.9\%). Focusing on learners' performance two months after the implementation of the instructional treatment (delayed post-test), Table 2 shows that they kept using all the different types of complaint formulas. In fact, the trend was similar to that found immediately after receiving instruction, as the no explicit reproach strategy was still the highest formula employed amounting to a $51.5 \%$, followed by explicit complaint (18.2\%), expression of disapproval (15.9\%), expressions of accusation and warning (7.2\%) and expressions of threat (7.2\%).

These findings seem to indicate, in line with Lyster's (1994) and Martínez-Flor's (2012) studies that provided evidence of the positive effects of instruction one and four months later respectively, that learners' use of appropriate complaint formulas was retained two months after having participated in the instructional period. In fact, learners kept a high use of the no explicit reproach formula indicating thus that they paid attention to the importance of softening their complaints in order not to be perceived as rude or impolite. Additionally, learners' responses were still longer and much more elaborated than those found in the pre-test, and when the expressions of disapproval, accusation and warning as well as threat were used, they were softened and mitigated.

The following example from Scenario 2 of the IDCT (Usó-Juan and Martínez-Flor, 2014) illustrates this fact by presenting learner's complaining performance on the three different moments. 
You are a receptionist in a two-star hotel. You are applying for the position of head receptionist in a highly reputed hotel. The interview committee wants to have a recommendation letter from your employer. The hotel general manager, who you barely know, agrees to write this letter. When you read the letter, you discover it only gives generic bromides about your current job. You think your excellent job in the hotel deserves more than a generic letter of recommendation. You go to your boss' office to talk about this fact. You explain:

- Pre-test: Thank you for the letter sir, but it is very generic. You have only included general information about what I do in my current job. Could you rewrite it?

- Post-test: I would like to talk to you about the letter of recommendation. I don't want to seem ungrateful, but I expected a more suitable letter because I have been working very hard. Maybe you were very busy and still are at the moment, but I would like to ask you if you could reconsider writing it again.

- Delayed post-test: I would like to talk to you about the generic letter of recommendation you wrote about me. I am pleased you wrote it, as I know you are very busy, but it is a little bit general. If it is not much trouble, I would appreciate very much if you could write a more elaborated letter for me.

The previous example shows that before receiving instruction, the only formula used was that of "explicit complaint" (it is very generic, you have only included general information). Contrarily, after the instructional treatment, although the learners' response also included a kind of "explicit complaint" (I expected a more suitable letter), this was softened with the use of another formula, that of "no explicit reproach" which showed an understanding of the situation (Maybe you were very busy). Additionally, the learner mitigated to a great extent his/her complaint by using expressions such as I don't want to seem ungrateful, but ... or I would like to ask you if you could ... Finally, the same learner's performance in this situation two months later included a softened "explicit complaint" (it is a little bit general) preceded by a "no explicit reproach" formula (I know you are very busy). Similarly, the complaint was also mitigated with different expressions, such as I am pleased you wrote it ... or If it is not much trouble, I would appreciate very much if you could ...

\section{Conclusion}

The main aim of the present study was to examine the long-term effects of pragmatic instruction on EFL learners' use of complaint formulas before participating in an instructional period, immediately after it, and two months later. Results have shown that after receiving instruction learners employed a high number of appropriate complaint formulas as well as different types of them. Additionally, a similar pattern was observed two months after the instruction had finished. These results contribute therefore to that research that has ascertained the importance of incorporating pragmatic instruction in FL contexts, whose benefits are seen not only in the short term but also some time after finishing its implementation.

Despite these positive findings, it is worth mentioning that we do not know if similar results would have been obtained with a different target population. Indeed, Codina's (2008) research showed that instruction seemed to be positive for advanced learners, but not for low proficiency students (either in the short or in the long term). Therefore, the issue of examining particular individual variables, such as proficiency, deserves further empirical and qualitative research. In this way, we could extend our understanding of how pragmatics can be successfully integrated in FL settings. 


\section{Notes}

As members of the LAELA (Lingüística Aplicada a l’Ensenyament de la Llengua Anglesa) research group, we would like to acknowledge that this study is part of a research project funded by the Spanish Ministerio de Economía y Competitividad (FFI2012-38145).

\section{References}

Codina, V. (2008). "The immediate vs. delayed effect of instruction on mitigators in relation to the learner's language proficiency in English”. In Learning how to Request in an Instructed Language Learning Context, Eva Alcón Soler (ed.), 227-256. Bern: Peter Lang.

Kasper, G. and Rose, K. R. (2002). Pragmatic Development in a Second Language. Oxford: Blackwell.

Liddicoat, A. J. and Crozet, C. (2001). “Acquiring French interactional norms through instruction”. In Pragmatics in Language Teaching, Kenneth R. Rose and Gabriele Kasper (eds), 125-144. Cambridge: Cambridge University Press.

Lyster, R. (1994). "The effect of functional-analytical teaching on aspects of French immersion students' sociolinguistic competence”. Applied Linguistics 15 (3), 263-287.

Martínez-Flor, A. (2012). Examining EFL learners' long-term instructional effects when mitigating requests. In Economidou-Kogetsidis, M. and H. Woodfield (eds) Interlanguage Request Modificaction. Amsterdam: John Benjamins.

Martínez-Flor, A and Usó-Juan, E. (2010). Pragmatics and speech act performance. In MartínezFlor, A. and Usó-Juan, E. (eds.), Speech Act Performance: Theoretical, Empirical and Methodological Issues, 3-20. Amsterdam: John Benjamins.

Martínez-Flor, A. and Usó-Juan, E. (2015). The role of instruction on EFL learners' use of complaining-apologising semantic formulas. Procedia - Social and Behavioral Sciences, 212 (2), 2328.

Olshtain, E. and Weinbach, L. (1987). Complaints: A study of speech act behaviour among native and nonnative speakers of Hebrew. In J. Verschueren and M. Bertuccelli-Papi (Eds.), The pragmatic perspective: Selected papers from the 1985 International Pragmatics Conference (pp. 195-208). Amsterdam: John Benjamins.

Quick Placement Test (2001). Paper and Pen Test. Oxford: Oxford University Press.

Taguchi, N. (2015). Instructed pragmatics at a glance: Where instructional studies were, are, and should be going. Language Teaching, 48 (1), 1-50.

Takahashi, S. (2010). The effect of pragmatic instruction on speech act performance. In MartínezFlor, A. and Usó-Juan, E. (eds), Speech Act Performance: Theoretical, Empirical and Methodological Issues, 127-142. Amsterdam: John Benjamins.

Trosborg, A. (1995). Interlanguage pragmatics: Requests, complaints and apologies. Berlin: Mouton de Gruyter.

Usó-Juan, E. and Martínez-Flor, A. (2014). Reorienting the assessment of the conventional expressions of complaining and apologising: From single-response to interactive DCTs. Iranian Journal of Language Testing, 4 (1), 113-136. 